\title{
Mucin 1 and poly I:C activates dendritic cells and effectively eradicates pituitary tumors as a prophylactic vaccine
}

\author{
DEHUA SUI, LIXIN MA, MENG LI, WEI SHAO, HONGPENG DU, KE LI, ZHENZHU LI and ZEFU LI
}

\begin{abstract}
Department of Neurosurgery, Affiliated Hospital of Binzhou Medical College, Binzhou, Shandong 256603, P.R. China
\end{abstract}
Received February 11, 2015; Accepted December 2, 2015

DOI: $10.3892 / \mathrm{mmr} .2016 .4964$

\begin{abstract}
Pituitary tumors are the most common type of cancer within the central nervous system. In the present study, the expression levels of mucin 1 (Muc1) were examined in invasive and non-invasive pituitary tumor samples, and the results of immunohistochemical staining and Western blot analysis demonstrated marked positive expression of Muc1. In addition, Muc1 + polyinosinic:polycytidylic acid (poly I:C) was found to stimulate the expression levels of the surface molecules cluster of differentiation (CD)40, CD83 and CD80, and HLA-DRm and decreased the expression of CD14 in the dendritic cells, determined using fluorescence-activated cell sorting. The secretions of interleukin (IL)-6, tumor necrosis factor- $\alpha$ and IL- $1 \beta$ cytokines were also significantly induced, in a dose-dependent manner. In in vivo experiments, a higher percentage of $\mathrm{CD}^{+} \mathrm{CD}^{+} \mathrm{T}$ lymphocytes was detected, and the levels of interferon- $\gamma$ and IL-2 in the splenocytes were also upregulated. Furthermore, the combination treatment of Muc1 with poly I:C increased anti-Muc1 IgM and anti-Muc1 IgG titers, and altered the balance of $\operatorname{IgG} 2 \mathrm{a}$ and $\mathrm{IgG} 1$, all of which increased the Thelper (Th)1 polarized immune response. Thus, the tumor antigen, Muc1, with poly I:C may produce potent protective effects, which polarize immune responses towards Th1, and elicit antitumor immunity to inhibit the progression of pituitary tumors.
\end{abstract}

\section{Introduction}

Pituitary tumors account for between 10 and $25 \%$ of all intracranial neoplasms (1). They represent the third most common type of cancer within the central nervous system, and is only less frequent than glioma and meningioma $(1,2)$. Pituitary tumors are also one of the most common tumors of the endocrine system (3). With the continuous development of

Correspondence to: Dr Zefu Li, Department of Neurosurgery, Affiliated Hospital of Binzhou Medical College, 661 Second Yellow River Road, Binzhou, Shandong 256603, P.R. China

E-mail: leezefu_best@163.com

Key words: pituitary tumors, cytokines, mucin1, dendritic cells, $\mathrm{T}$ helper 1 response diagnostic imaging and laboratory diagnosis, the incidence of pituitary tumors has gradually increased (4). Clinically, the most common classification methods for pituitary tumors are based on their endocrine function and immunohistochemistry staining analysis. Pituitary adenomas are classified based upon anatomical, histological and functional criteria (5), including lactotrophic adenomas (prolactinomas), somatotrophic adenomas, corticotrophicadenomas, gonadotrophicadenomas, thyrotrophic adenomas (rare) and null cell adenomas (6,7). Lactotrophic adenomas, secreting prolactin, account for $30 \%$, somatotrophic adenomas account for $15 \%$ and non-secretive null cell adenomas account for $25 \%$ of pituitary adenomas $(8,9)$.

Although several techniques and drugs have been investigated and used in the treatment of pituitary cancer, there has been no significant improvement in the local control of carcinoma development and progression, and there have been no significant improvements in survival rates or in quality of life of patients with pituitary cancer $(10,11)$. Following its rapid development in cancer therapy, immunotherapy has generally become one of the important treatment strategies following surgery, radiation therapy and chemotherapy $(12,13)$. Provenge is a dendritic cell (DC)-based therapeutic cancer vaccine, which was approved by the Food and Drug Administration in April 2010 (14,15), until which DCs were first approved for the treatment of advanced prostate cancer. Currently, DC immunotherapy is broadly used in clinical therapy, and is used in the treatment of breast cancer, lung cancer, gastrointestinal cancer, prostate cancer, kidney cancer and malignant melanoma (16-20). DC immunotherapy has a broad range of applications, is safe and has no significant adverse reactions $(21,22)$.

Mucins are a family of high molecular weight, heavily glycosylated proteins (23). To date, over 20 mucin genes have been identified and cloned, including membrane-bound Muc1, Muc3, Muc4 and Muc12, and secreted Muc2, Muc5, Muc6 and Muc9 (24,25). Muc1 is an epithelial membrane associated glycoprotein (Episialin), and it is the first mucin to be characterized and cloned in detail (26). An increasing number of mucins are being used as important molecular markers. In the present study, polyinosinic:polycytidylic acid (poly I:C) was used as an immunostimulatory agent or immune adjuvant. The present study also aimed to investigate whether Muc1 offers potential as a candidate vaccine antigen to prevent or control the progression of pituitary tumors in vitro and in vivo. 


\section{Materials and methods}

Cell line and reagents. The AtT20 cell line was obtained from American Type Culture Collection (cat. no. CRL1795), and the cells were cultured in Dulbecco's modified Eagle's medium (DMEM; Invitrogen; Thermo Fisher Scientific, Inc., Waltham, MA, USA) supplemented with $10 \%$ fetal bovine serum (FBS; Thermo Trace, Ltd., Melbourne, Australia) at $37^{\circ} \mathrm{C}$ in an atmosphere of $95 \%$ air and $5 \% \mathrm{CO}_{2}$. Human recombinant Mucl protein was obtained from Abnova Corporation (Tapei City, Taiwan). Mouse anti-human MUC1 (sc-59795) and anti-human $\beta$-actin (sc-69879) monoclonal antibodies (mAbs), and horseradish peroxidase (HRP)-conjugated goat anti-mouse secondary antibody (sc-2031) were obtained from Santa Cruz Biotechnology, Inc (Santa Cruz, CA, USA).

Patients. A total of 42 patients with invasive pituitary adenoma, and 44 patients with non-invasive pituitary adenoma, at the Affiliated Hospital of Binzhou Medical College (Binzhou, China) were enrolled in the present study. Pituitary adenoma specimens were collected during surgery in order to detect the expression levels of Mucl by immunohistochemistry and western blotting. The samples were maintained at $-80^{\circ} \mathrm{C}$ until further analysis. The present study was approved by the ethics committee of Affiliated Hospital of Binzhou Medical College. Written informed consent was obtained from all patients.

Immunohistochemical analysis. Immunohistochemical staining was performed in order to detect the expression of Muc1 in the pituitary adenoma specimens. Paraffin-embedded sections were de-waxed, rehydrated, blocked and incubated overnight with mouse anti-human MUC1 $(1: 1,000)$ and anti-human $\beta$-actin $(1: 1,000) \mathrm{mAbs}$. Subsequently, the specimens were washed three times and incubated with HRP-conjugated goat anti-mouse secondary antibody $(1: 1,000)$ for $1 \mathrm{~h}$. The stained slides were dehydrated, made transparent, mounted in Permount and visualized using a Nikon Eclipse Ti-E microscope (Nikon Corporation, Tokyo, Japan). The images were captured with a camera attached to the microscope at x400 magnification.

Western blotting. The invasive and non-invasive pituitary adenoma specimens were lysed using radioimmunoprecipitation assay buffer (Beyotime Institute of Biotechnology, Shanghai, China) consisting of $50 \mathrm{mmol} / \mathrm{l}$ Tris, $1 \% \mathrm{NP}-40,150 \mathrm{mmol} / \mathrm{l}$ $\mathrm{NaCl}, 1.0 \mathrm{mmol} / \mathrm{l} \mathrm{EDTA}, 0.1 \%$ sodium dodecyl sulfate (SDS) and $0.25 \%$ SDC. Equal quantities of protein $(10 \mu \mathrm{g})$ were separated by $10 \%$ SDS-polyacrylamide gel electrophoresis and blotted onto polyvinylidene difluoride membranes. After blocking the membranes with 5\% bovine serum albumin (Beyotime Institute of Biotechnology) in phosphate-buffered saline, the membranes were incubated with mouse anti-MUC1 and anti- $\beta$-actin $\mathrm{mAbs}$ $(1: 1,000)$ at $4^{\circ} \mathrm{C}$ overnight. Subsequently, the membranes were washed three times with PBS containing 0.05\% Tween-20 (PBST), followed by incubation with HRP-conjugated goat anti-mouse secondary antibody $(1: 1,000)$ at room temperature for $40 \mathrm{~min}$. The membranes were visualized using the Pierce ECL Western Blotting Substrate (cat. no. 32209; Thermo Fisher Scientific, Inc.), and blot intensities were analyzed using ImageJ software, version 2 (National Institutes of Health, Bethesda, MA, USA).
Phenotype identification of peripheral blood mononuclear cell (PBMC)-derived DCs by fluorescence-activated cell sorting (FACS) analysis. The DCs were generated and cultured from human PBMCs, as described in a previous study (27). The PBMCs were obtained from blood samples derived from healthy donors using Ficoll-Hypaque density gradient centrifugation at $300 \mathrm{x}$ g for $5 \mathrm{~min}$ at $37^{\circ} \mathrm{C}$. The PBMCs $\left(5 \times 10^{4}\right.$ cells/well) were plated into 6 -well plates. Following 5 days of culture, human immature DCs were stimulated with $50 \mu \mathrm{g} / \mathrm{ml} \mathrm{Muc1} \mathrm{and}$ $50 \mu \mathrm{g} / \mathrm{ml}$ poly I:C, or with $50 \mu \mathrm{g} / \mathrm{ml} \mathrm{Mucl}$ alone for $48 \mathrm{~h}$ at $37^{\circ} \mathrm{C}$. Subsequently, the cells were collected and washed with PBS for phenotypic analysis. The DCs were stained with phycoerythrin (PE)-conjugated mAbs against CD40 (cat. no. 313005), CD80 (cat. no. 305207) and CD83 (cat. no. 305307), and fluorescein isothiocyanate (FITC)-conjugated mAbs against CD14 (cat. no. 325603) and histocompatability locus antigen (HLA)-DR (cat. no. 307603), as well as allophycocyanin anti-human CD86 mAb (cat. no. 305411; all BioLegend, San Diego, CA, USA) for 20 min at $4^{\circ} \mathrm{C}$ (all 1:1,000).

Determination of DC cytokine production using an enzyme-linked immunosorbent assay (ELISA). The human immature DCs were adjusted to a density of $5 \times 10^{5} \mathrm{cells} / \mathrm{ml}$ and plated into 24-well plates. The cells were treated with Muc1, Muc1 + poly I:C or lipopolysaccharide (LPS) for $48 \mathrm{~h}$, and the culture supernatants were harvested at the end of the experiment at $37^{\circ} \mathrm{C}$, and centrifuged at $300 \mathrm{xg}$ for $5 \mathrm{~min}$ at $37^{\circ} \mathrm{C}$, prior to ELISA assay. The levels of the cytokines tumor necrosis factor (TNF)- $\alpha$, interleukin (IL)-1 $\beta$ and IL-6 in the supernatants were measured, according to the manufacturer's protocol (Neobioscience Technology, Co., Ltd., Beijing, China).

Mice and immunization. A total of 18 C57BL/6 male mice (6-8 weeks old) were obtained from the Laboratory Animal Center of Peking University Health Science Center (Beijing, China). The mice were housed in specific pathogen-free conditions under a 12 -h light/dark cycle at $21-25^{\circ} \mathrm{C}$, and with ad libitum access to food and water. The mice were randomly assigned to three groups (6 mice/group), as follows: i) The Muc1 group; ii) the Muc1 + poly I:C group; and iii) the control group. The mice were twice injected subcutaneously on days 1 and 15 with $20 \mu \mathrm{g}$ Mucl antigen, $20 \mu \mathrm{g}$ Mucl antigen $+50 \mu \mathrm{g}$ poly I:C or with $100 \mu \mathrm{l}$ PBS. The mice were sacrificed by cervical dislocation 7 days following the final immunization and the abdominal cavity was opened with scissors in order to obtain the spleens. Splenocyte cell suspensions were prepared using a sterile syringe core and 200 mesh steel filter.

Previous studies have reported that tumor cell lysate (TLA), which is used as a source of tumor-specific antigens, is able to induce the maturation of dendritic cells; although the maturation-inducing effect of TLAs was not particularly strong $(11,12)$. In the present study, the mice were vaccinated with TLA or TLA + poly I:C, and the protein expression levels of interferon (IFN) $\gamma$ and IL-2 in the splenocytes of the mice were investigated using the Mouse IFN- $\gamma$ ELISA (cat. no. EM0560) and the Mouse IL-2 ELISA kit (cat. no. EM0290), respectively (both Beijing Solarbio Science \& Technology Co., Ltd., Beijing, China). The TLA was obtained from the AtT20 cells. Briefly, cells were washed once with PBS, harvested and then resuspended in PBS at $1 \times 10^{7}$ cells $/ \mathrm{ml}$, prior to 5 cycles 
Table I. Comparison of the expression levels of mucin 1 in pituitary adenoma tissues.

\begin{tabular}{lcccc}
\hline Type of tissue & $\begin{array}{c}\text { Negative } \\
\text { expression }\end{array}$ & $\begin{array}{c}\text { Weak positive } \\
\text { expression }\end{array}$ & $\begin{array}{c}\text { Strong positive } \\
\text { expression }\end{array}$ & 32 \\
Invasive pituitary adenoma & 4 & 6 & 90.4 \\
Non-invasive pituitary adenoma & 35 & 9 & 20.5 \\
\hline
\end{tabular}

A
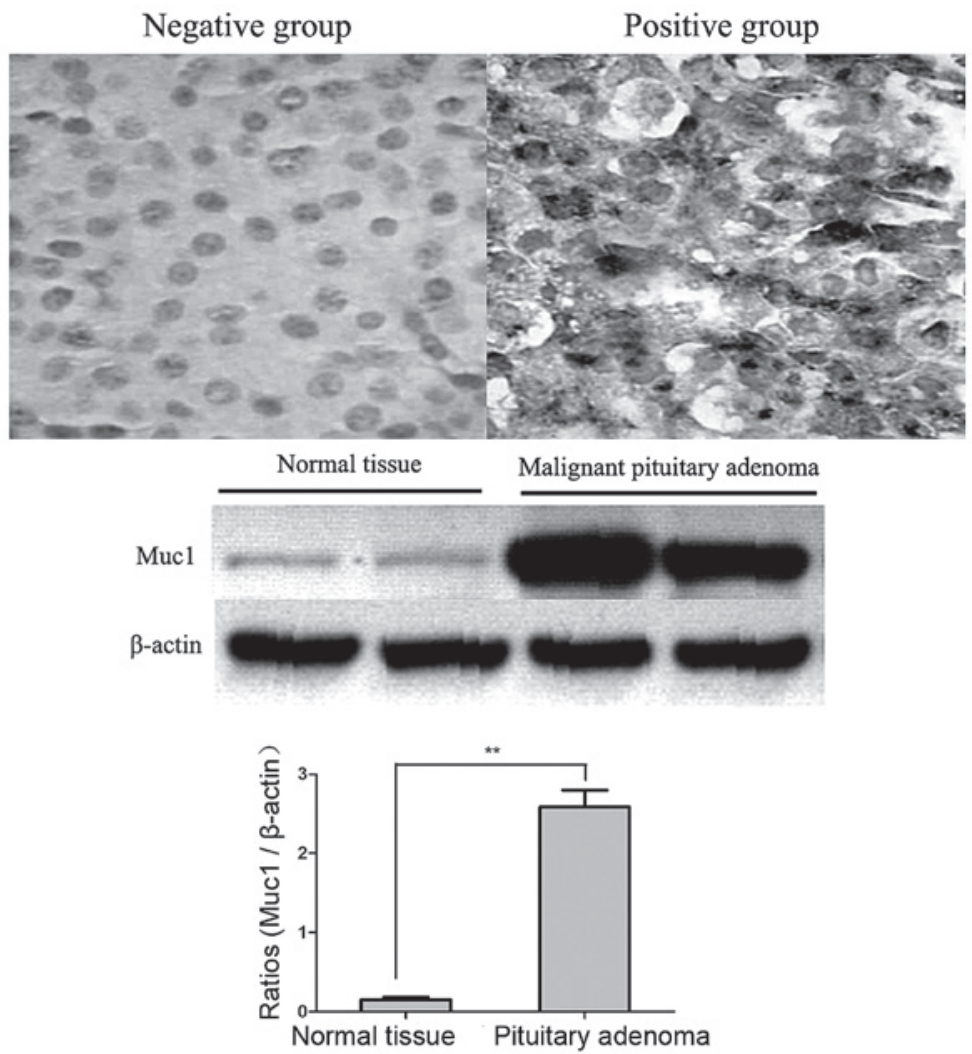

Figure 1. Paraffin-embedded samples were analyzed using histochemical staining for the expression of Muc1. (A) Negative expression of Muc1 in non-invasive pituitary adenomas, and positive expression of Muc1 in invasive pituitary adenomas, with dark brown or brown particles (magnification, x200); (B) Protein expression levels of Mucl in the non-invasive pituitary tissue and malignant pituitary adenoma were detected by western blotting. Two representative samples from each group are shown. $\beta$-actin was used as an internal reference. Data are presented as the mean \pm standard deviation. ${ }^{* *} \mathrm{P}<0.01$ vs. the normal tissue. Muc1, mucin 1.

of freezing using methanol with dry ice and thawing at $56^{\circ} \mathrm{C}$. Subsequently, the cells were harvested, and washed in PBS, prior to centrifugation at $1,700 \mathrm{x} g$ for $5 \mathrm{~min}$. The TLAs were contained in the supernatant, which were separated and stored at $-80^{\circ} \mathrm{C}$ prior to vaccination of the mice.

T-cell subtype analysis by FACS analysis. The T-cell subtype was determined using FACS analysis. At 10 days following the second immunization (day 15), blood samples were taken from the venous plexus of the mouse eyes and $50 \mu \mathrm{l}$ heparin-treated orbital blood was lysed with red blood cell lysis buffer (eBioscience, San Diego, CA, USA). Lymphocytes were stained with $100 \mu \mathrm{l}$ PBS containing 1\% BSA and $0.1 \%$ $\mathrm{NaN}_{3}$, together with $5 \mu \mathrm{l}$ FITC-conjugated anti-CD3 mAb (cat. no. 16-0037-81), followed by simultaneous staining with $5 \mu \mathrm{l}$ of PE-labeled anti-CD4 (cat. no. 12-0048-41) or anti-CD8 (cat. no. 12-0809-41) mAbs (all eBioscience). The cells were then incubated for $20 \mathrm{~min}$ at $4^{\circ} \mathrm{C}$, and flow cytometry was performed using the BD FACSCalibur flow cytometer (BD Biosciences, Franklin Lakes, NJ, USA).

Measurement of Mucl-specific antibodies. Muc1-specific antibodies in the mouse serum were measured using an ELISA (28). Firstly, microtiter plates (Nalge Nunc International, Penfield, NY, USA) were coated with Muc1 $(10 \mu \mathrm{g} / \mathrm{ml})$ in $50 \mathrm{mM}$ carbonate buffer ( $\mathrm{pH} 9.6$ ) overnight at $4^{\circ} \mathrm{C}$. Following washing with PBST, the wells were blocked with $100 \mu 15 \%$ dried milk in PBST for $4 \mathrm{~h}$ at $37^{\circ} \mathrm{C}$. To measure $\operatorname{IgM}, \operatorname{IgG}, \operatorname{IgG} 2 \mathrm{a}$ and $\mathrm{IgG} 1$, the plates containing with serum samples were incubated with HRP-conjugated rabbit anti-mouse $\mathrm{IgG}$ for $30 \mathrm{~min}$ at $37^{\circ} \mathrm{C}$. Following incubation with substrate buffer, the enzyme reaction was terminated after $5 \mathrm{~min}$ by adding $50 \mu \mathrm{l} 2 \mathrm{M} \mathrm{H}_{2} \mathrm{SO}_{4}$. The absorbance at $450 \mathrm{~nm}$ was then measured using the Multiskan MK3 microplate reader (Thermo Fisher Scientific, Inc.). All washes were performed using PBS-T. Serum samples and HRP-conjugated rabbit anti-mouse IgG (sc-358914; 
A

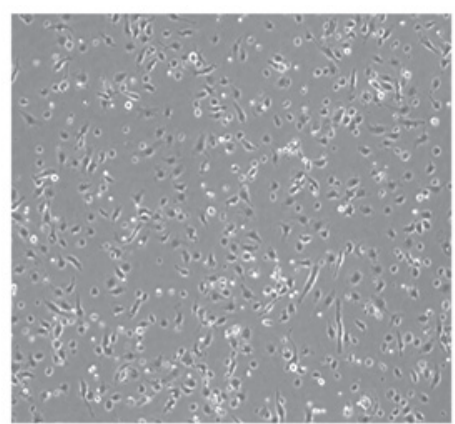

C

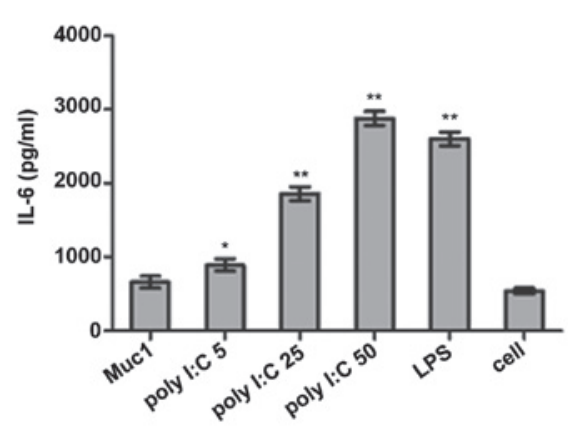

B

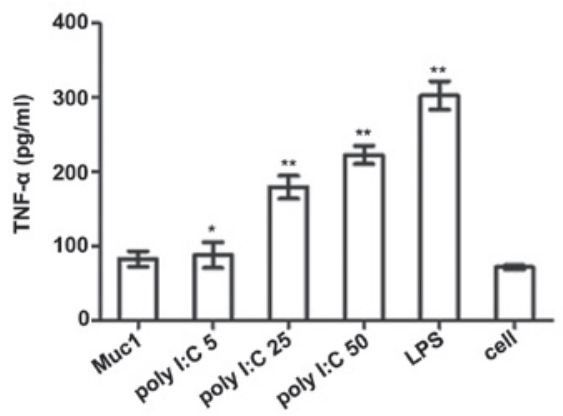

D

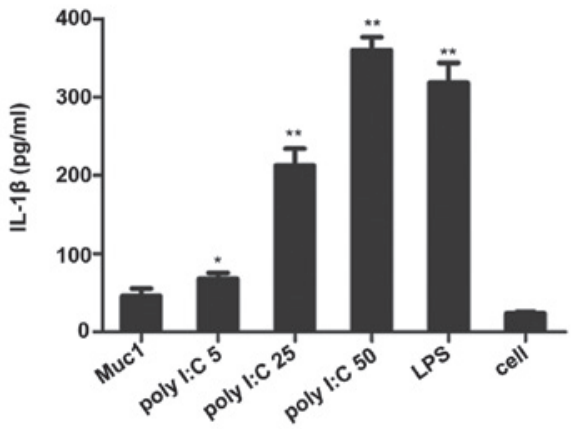

Figure 2. Cytokine production in human DCs in the Muc1 + poly I:C group and poly I:C group. (A) Image of human DCs generated from PBMCs and cultured in medium supplemented with human granulocyte-macrophage colony-stimulating factor and IL-4 on day 5 (magnification, $\mathrm{x} 100$ ). PBMC-derived DCs were stimulated with different concentrations of poly I:C (5, 25 and $50 \mu \mathrm{g} / \mathrm{ml})$ for $24 \mathrm{~h}$, and the levels of (B) TNF- $\alpha$, (C) IL-6 and (D) IL-1 $\beta$ cytokines in the supernatants were measured using enzyme-linked immunosorbent assays. Untreated cells were used as a negative control, and lipopolysaccharide (20 ng/ml) was used as a positive control. Data are presented as the mean \pm standard deviation. ${ }^{*} \mathrm{P}<0.05$ and ${ }^{* *} \mathrm{P}<0.01$ vs. the untreated cells. DCs, dendritic cells; Muc1, mucin 1; poly I:C, polyinosinic: polycytidylic acid; PBMCs, peripheral blood mononuclear cells; LPS, lipopolysaccharide; IL, interleukin; TNF- $\alpha$, tumor necrosis factor- $\alpha$.

1:2,000; Santa Cruz Biotechnology, Inc.) were diluted in PBS-T containing $3 \%$ dried milk.

Cytotoxicity assay. Lactate dehydrogenase (LDH) release assays were performed according to the manufacturer's protocol (KeyGen Biotech Co., Ltd., Nanjing, China). The C57BL/6 mice were immunized, as described above and, 10 days following the final immunization, splenocytes were prepared as effector cells, and AtT20 cells were used as target cells. Cytolytic T lymphocyte activity was measured by a LDH release assay in 96-well round-bottom plates. Target cells ( $2 \times 10^{4}$ cells per well) in a volume of $100 \mu$ l were incubated with $100 \mu 1$ effector cells at 5/1,10/1 or 20/1 effector:target (E:T) ratios for $24 \mathrm{~h}$ at $37^{\circ} \mathrm{C}$ in phenol red-free DMEM containing $2 \% \mathrm{FBS}$. Following centrifugation at $300 \mathrm{x}$ g for $5 \mathrm{~min}$ at $37^{\circ} \mathrm{C}$, the supernatants (50 $\mu \mathrm{l}$ per well) were transferred into 96 -well flat-bottom plates for measurement of absorbance at $490 \mathrm{~nm}$ using the Multiskan MK3 microplate reader.

Statistical analysis. Data were analyzed using SPSS software, version 19.0 (IBM SPSS, Armonk, NY, USA). Data are presented as the mean \pm standard deviation. Statistical significance in the different treatment groups was compared using a log-rank test. $\mathrm{P}<0.05$ was considered to indicate a statistically significant difference.

\section{Results}

Positive Mucl staining is observed in invasive pituitary adenoma. In the present study, 42 registered cases of invasive pituitary adenoma, and 44 samples of non-invasive pituitary adenoma were included from the hospital database. The expression of Mucl was detected using immunohistochemistry in the invasive and non-invasive pituitary adenomas, respectively. As shown in Fig. 1A, marked positive expression of Muc1 was observed, with dark brown or brown particles, which were predominantly located in the cytoplasm and membrane. By contrast, negative or weak staining of Mucl was observed in the non-invasive pituitary adenomas. The positive rates of Mucl expression in the invasive and non-invasive pituitary adenomas were $90.4 \%$ (32/42) and 20.5\% (9/44), respectively (Table I). There was a significant difference between the two groups $(\mathrm{P}<0.01)$. The expression levels of Mucl were also determined in samples of non-invasive pituitary tissues and malignant pituitary adenomas by western blotting, and the results were consistent with those obtained by the immunohistochemical staining (Fig. 1B).

Production of cytokines in human DCs in the Mucl + poly I:C group and poly I:C group. In the present study, DCs were derived from adherent PBMCs cultured in medium supplemented with human granulocyte-macrophage colony-stimulating factor and IL-4, and the DCs are shown in Fig. 2A. As Muc1 was expressed at high levels in the malignant pituitary adenomas, Mucl was used as the tumor antigen, and poly I:C was selected as an immune stimulator agent. Cytokine secretion was examined following stimulation of the immature PBMC-DCs with Muc1 or different concentrations of Poly I:C, and the resulting supernatants were harvested after $48 \mathrm{~h}$. As shown in Fig. 2B-D, poly $\mathrm{I}: \mathrm{C}$ significantly enhanced the secretion of IL-1 $\beta$, TNF- $\alpha$ and 
$\mathbf{A}$
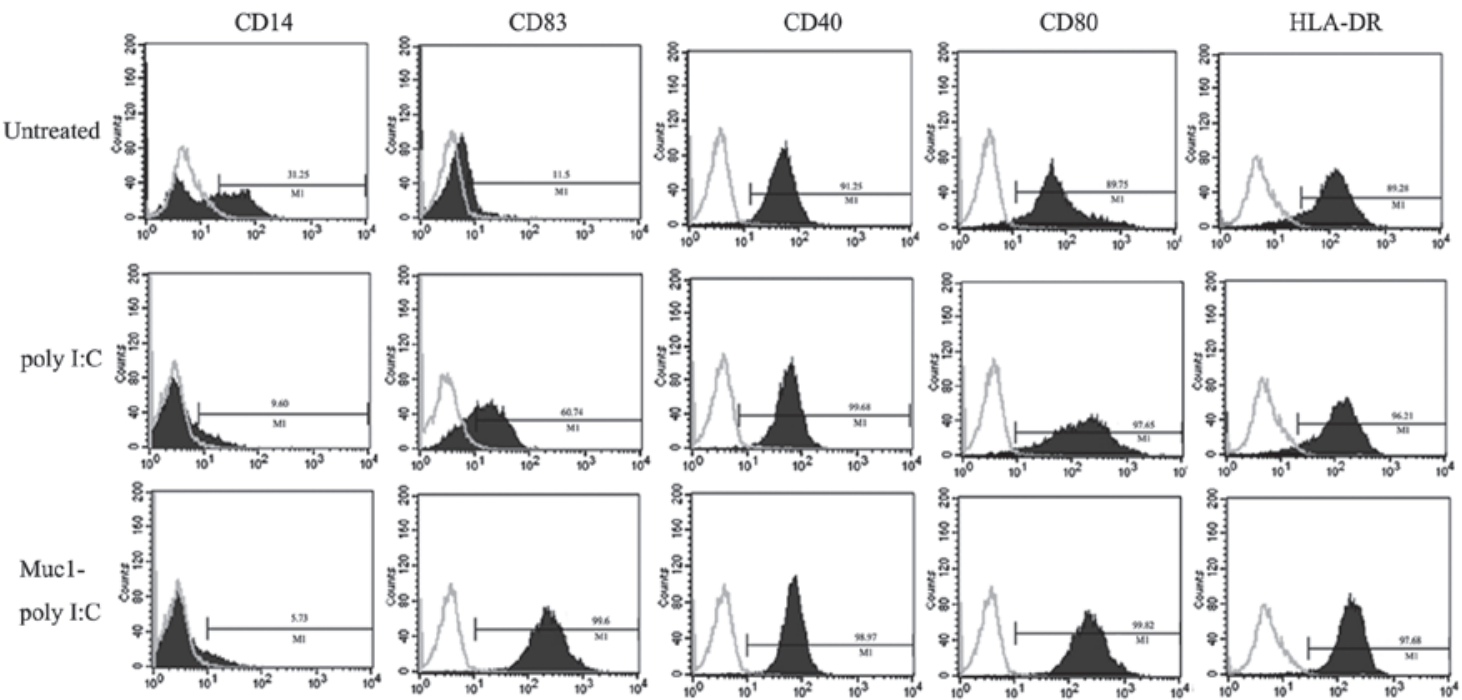

B

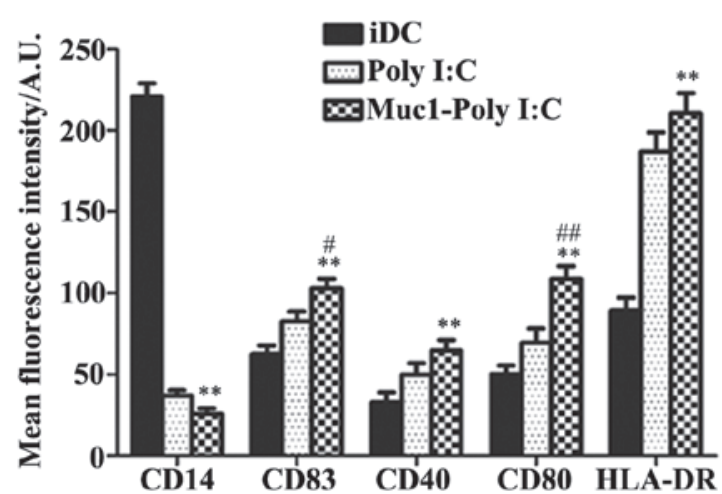

Figure 3. Phenotypic identification of PBMC-derived DCs. (A) Phenotypic maturation of PBMC-derived DCs was induced. Human PBMCs were cultured for 5 days with granulocyte-macrophage colony-stimulating factor and IL-4, and immature monocyte-derived DCs were generated. The iDCs were then stimulated with $50 \mu \mathrm{g} / \mathrm{ml}$ poly I:C or poly I:C + Mucl. The cells were harvested and the expression of cell surface markers were determined using flow cytometry after $48 \mathrm{~h}$. (B) Mean fluorescence intensities from three independent experiments. Untreated iDCs were used as negative controls. * P $>0.01$ vs. the iDC group; ${ }^{\#} \mathrm{P}<0.05$ and ${ }^{\# \prime} \mathrm{P}<0.01$ vs. the poly I:C group. iDCs, immature dendritic cells; Muc1, mucin 1; poly I:C, polyinosinic: polycytidylic acid; PBMCs, peripheral blood mononuclear cells; IL, interleukin; CD, cluster of differentiation; HLA, histocompatability locus antigen.

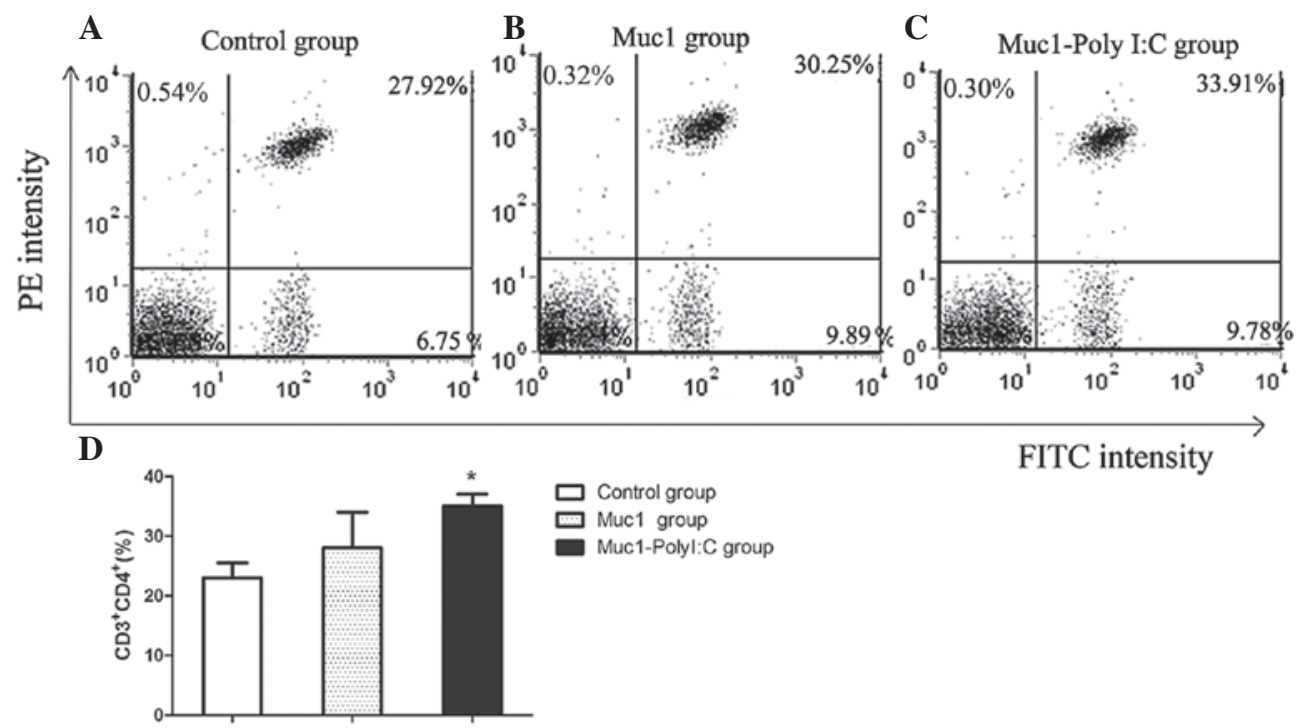

Figure 4. $\mathrm{CD}^{+} \mathrm{CD}^{+} \mathrm{T}$-cell subpopulations in the (A) control group, (B) Muc1 group and (C) Muc1 + poly I:C group, as determined by fluorescence-activated cell sorting. Mice were immunized and peripheral blood samples were collected from the mouse eyes. The lymphocytes were stained for the T-cell surface markers, CD3 and CD4. CD3 was detected using a FITC-conjugated monoclonal antibody and CD4 was detected using a PE-conjugated monoclonal antibody. The percentages in the graphs represent the ratios of $\mathrm{CD}^{+}, \mathrm{CD}^{+}$or $\mathrm{CD} 3^{+} / \mathrm{CD} 4^{+}$dural positive cells. (D) The percentages of $\mathrm{CD}^{+} / \mathrm{CD}^{+} \mathrm{T}^{-}$-cell subpopulations in the three groups are presented in a histogram. Data are presented as the mean \pm standard deviation. ${ }^{*} \mathrm{P}<0.05$ vs. the control group ( $\mathrm{n}=6$ ). Muc1, mucin 1; poly I:C, polyinosinic: polycytidylic acid; FITC, fluorescein isothiocyanate; PE, phycoerythrin; CD, cluster of differentiation. 

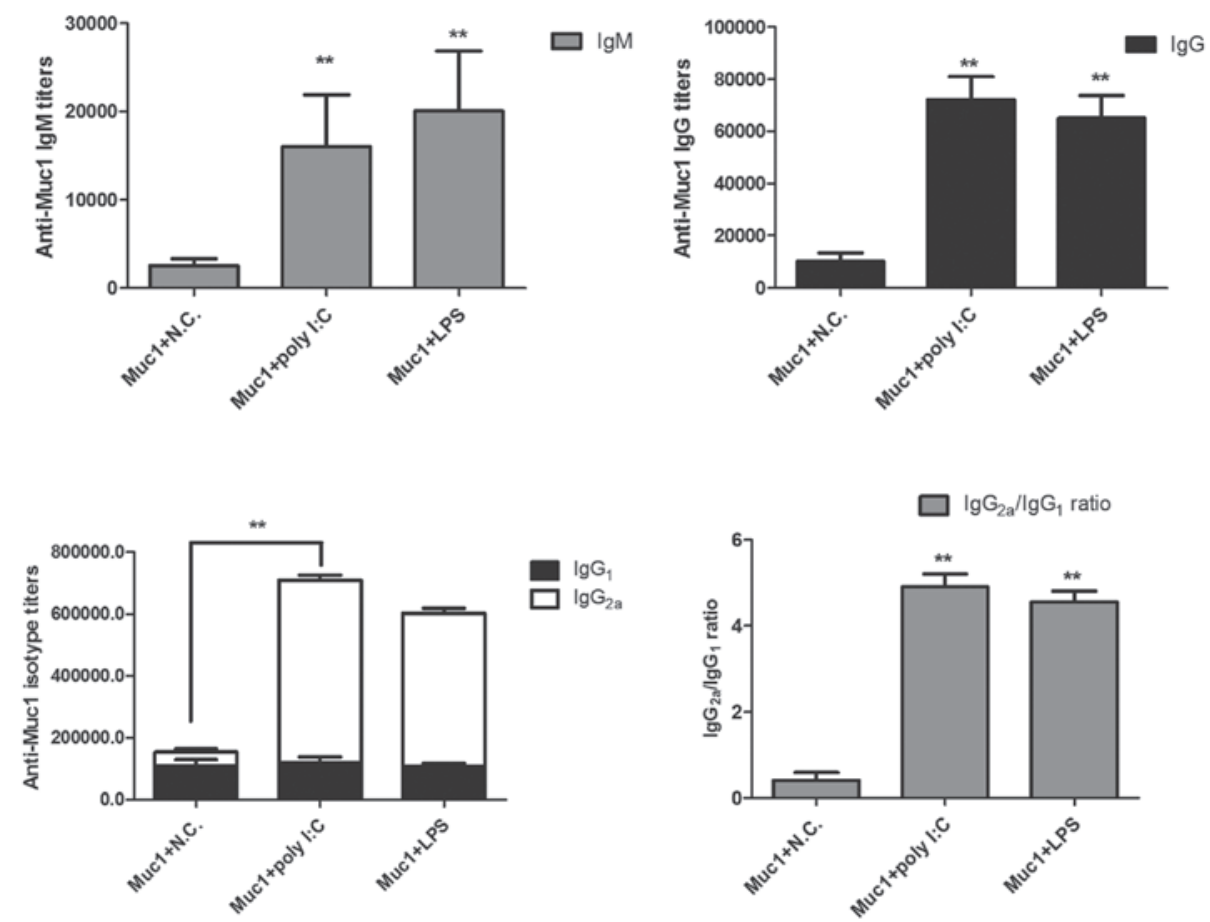

Figure 5. Muc1 + poly I:C increases anti-Muc1 IgM and IgG titers, and alters the IgG2a and IgG1 balance. Mice were immunized with Muc1 + phosphate-buffered saline (N.C), Muc1 + LPS or Muc1 + poly I:C, and at 10 days following final inoculation, peripheral blood samples were collected from the venous plexus of the eye and serum antibody titers were measured using an enzyme-linked immunosorbent assay $(n=8)$. Data are expressed as the mean \pm standard error of the mean. ${ }^{* *} \mathrm{P}<0.01$, compared with the N.C. group. Muc1, mucin 1; poly I:C, polyinosinic: polycytidylic acid.
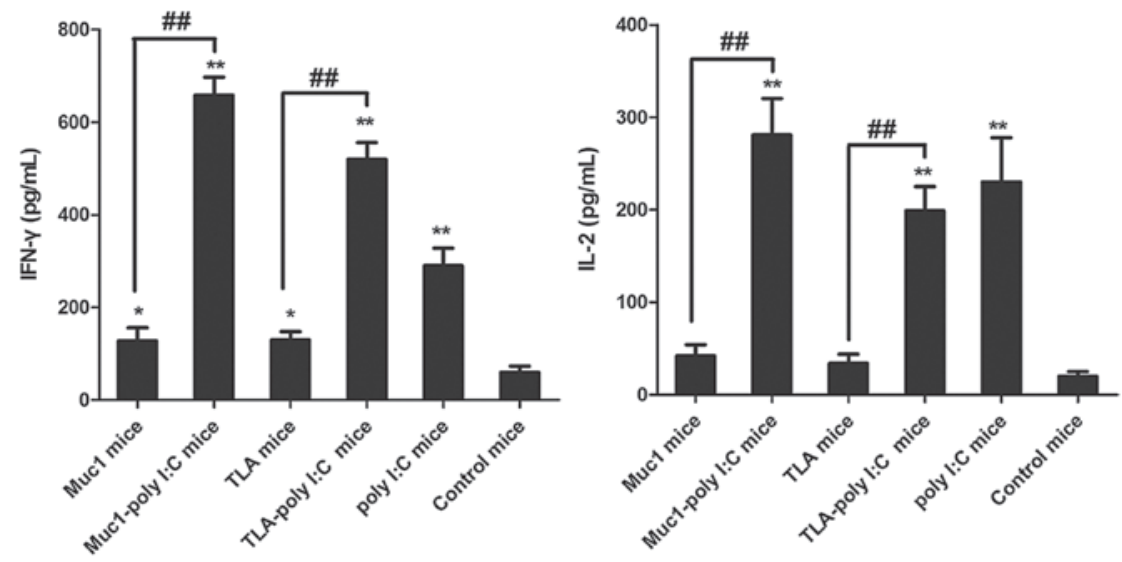

Figure 6. Levels of IFN- $\gamma$ and IL-2 in splenocytes harvested from immunized mice following in vitro re-stimulation. At 7 days following the final immunization, splenocytes were isolated and incubated in vitro with Mucl or TLA for $24 \mathrm{~h}$. The levels of IFN- $\gamma$ and IL-2 cytokines in the supernatant of the cultured splenocyte cells were determined. Data are expressed as the mean \pm standard deviation. ${ }^{*} \mathrm{P}<0.05$ and ${ }^{* *} \mathrm{P}<0.01$ vs. the control. ${ }^{\# /} \mathrm{P}<0.01$ vs. the Muc1 mice. Muc1, mucin 1; poly I:C, polyinosinic: polycytidylic acid; TLA, tumor lysate antigen; IFN, interferon; IL, interleukin.

IL-6 in a dose-dependent manner, as determined using ELISA. In this experiment, untreated cells were used as negative controls and cells treated with LPS were used as positive controls.

Phenotypic identification of PBMC-derived DCs. In order to assess the phenotypic variation of the human DCs, the expression of surface markers on the PBMC-derived DCs was examined using FACS analysis. The immature DCs were treated with either $50 \mu \mathrm{g} / \mathrm{ml}$ poly I:C or with $50 \mu \mathrm{g} / \mathrm{ml}$ poly I:C $+50 \mu \mathrm{g} / \mathrm{ml}$ Muc1 for $48 \mathrm{~h}$, following which the expression levels of costimulatory molecules (CD40 and CD80), HLA-DR and the CD83 maturation marker were measured.
As shown in Fig. 3A and B, the results demonstrated that poly I:C or Muc1-poly I:C induced the phenotypic maturation of the human DCs, with low expression levels of CD14, moderate expression levels of CD40, CD80 and CD83, and marked expression of HLA-DR.

Determination of $\mathrm{CD}^{+} \mathrm{CD}^{+} \mathrm{T}$ cell sub-populations using FACS analysis. In order to detect the immune response in vivo, C57BL/6 mice were used as an animal model. As is already known, T-cell subsets include $\mathrm{T}$ helper cells $\left(\mathrm{CD}^{+}{ }^{+} \mathrm{CD}^{+} \mathrm{T}\right.$ lymphocytes) and cytotoxic $\mathrm{T}$ cells $\left(\mathrm{CD}^{+} \mathrm{CD}^{+} \mathrm{T}\right.$ lymphocytes) (29). As shown in Fig. 4A-D, the mice immunized with 


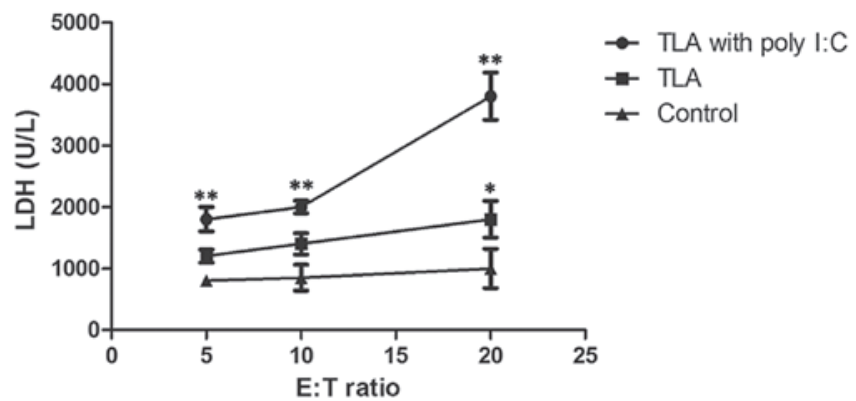

Figure 7. CTL activity was higher in the TLA-poly I:C group, as compared with the TLA group. C57BL/6 mice were immunized and, 7 days following the final immunization, damage to the membranes of AtT- 20 cells was evaluated in a $24 \mathrm{~h}$ cytotoxicity assay, by measuring LDH release. LDH release assays were performed with splenocytes as effector cells and AtT-20 as target cells. Specific lysis was calculated as follows: Lysis $(\%)=[($ experimental LDH release) - (spontaneous LDH release)] / [(maximum LDH release) - (spontaneous LDH release)] x 100. The CTL activity of the TLA + poly I:C group was significantly higher, compared with the control group $\left({ }^{* *} \mathrm{P}<0.05\right)$. All experiments were repeated twice and the results are expressed as the mean \pm standard error of the mean. CTL, cytotoxic T cell; TLA, tumor lysate antigen; poly I:C, polyinosinic: polycytidylic acid; LDH, lactate dehydrogenase; E:T, effector:target.

Muc1 + poly I:C contained a higher percentage of $\mathrm{CD}^{+} \mathrm{CD}^{+}$ $\mathrm{T}$ lymphocytes in their peripheral blood, compared with the mice injected with the negative control, PBS. However, the percentage of $\mathrm{CD}^{+} \mathrm{CD}^{+} \mathrm{T}$ lymphocytes in the peripheral blood did not change significantly (data not shown).

Mice immunized with Mucl + poly I:C have increased Mucl-specific serum antibody titers following vaccination. The present study also measured antigen-specific antibody titers in the immunized mice. Mucl antigen was injected subcutaneously into mice, together with poly I:C, with Mucl antigen only or with LPS and 10 days following the final immunization, the levels of IgM, total IgG, IgG2a and IgG1 of the anti-HBs antibodies were examined. As shown in Fig. 5, the mice immunized with Mucl + poly I:C had a higher geometric mean titer of Mucl antibodies, compared with the mice immunized with the antigen alone. In addition, IgM titers in the Muc1 + poly I:C group increased by 6.4 times, and $\mathrm{IgG}$ titers increased by 7.2 times, compared with the Mucl group. Of note, ploy I:C altered the balance of $\mathrm{IgG} 2 \mathrm{a}$ and $\mathrm{IgG} 1$, inducing more extensive production of $\operatorname{IgG} 2 \mathrm{a}$ antibody, compared with the control group. It has been reported that $\operatorname{IgG} 2 \mathrm{a}$ is directly associated with the $\mathrm{T}$ helper (Th)1 cell-mediated immune response, whereas IgG1 is associated with the Th2 immune response (30). This suggests that Muc1 + poly I:C may be involved in modulating cellular immunity, with positive effects in preventing tumor progression.

IFN- $\gamma$ and IL-2 cytokines are increased in mice immunized with $M u c 1+$ poly I:C or TLA + poly I:C. Cytokine patterns can reflect effector populations of immune cells to a certain degree. Th1 cytokines activate macrophages, natural killer cells and cellular immunity, whereas Th2 cytokines tend to promote humoral immune response (31). In the present study, at 10 days following the final immunization, splenocytes in the different treatment groups were stimulated with Mucl at a concentration of $1 \mu \mathrm{g} / \mathrm{ml}$, and the production of the IFN- $\gamma$ and IL-2 Th1 cytokines were examined using an ELISA. As shown in Fig. 6A and B, the levels of IFN- $\gamma$ and IL-2 in the splenocytes of the mice immunized with Muc1 + ploy I:C were significantly higher, as compared with those of the mice immunized with Muc1 alone $(\mathrm{P}<0.01)$. The present study also used TLAs from AtT-20 cells as antigens, and the results demonstrated that the levels of IFN- $\gamma$ and IL-2 in the splenocytes of the mice immunized with TLA + poly I:C were significantly higher, as compared with those of the mice immunized with TLA alone $(\mathrm{P}<0.01)$.

Cytotoxic T cell (CTL) activity is increased following immunization with TLA + poly I:C, as compared with TLA alone. To demonstrate the cytotoxic activity of splenocytes from the immunized mice, the present study examined the release of cytosolic LDH into the culture medium by damaged AtT20 cells. At 10 days following the final immunization, damage to the membranes of the AtT2 0 cells was evaluated in a $24 \mathrm{~h}$ cytotoxicity assay by measuring $\mathrm{LDH}$ release. The $\mathrm{LDH}$ release assays were performed with splenocytes as effector cells and AtT20 cells as target cells. The E:T cell ratios were 5:1, 10:1 and 20:1. As shown in Fig. 7, the CTL response was significantly higher in the mice immunized with TLA + poly I:C, as compared with that in those the mice immunized with TLA alone $(\mathrm{P}<0.01)$ or with $\mathrm{PBS}(\mathrm{P}<0.01)$, which demonstrated that TLA + poly I:C effectively induced cytotoxic activity to induce tumor cell death.

\section{Discussion}

Cancer can be treated using several techniques, including surgery, chemotherapy, radiation therapy, immunotherapy and $\mathrm{mAb}$ therapy. Cancer immunotherapy has emerged as one of the four most commonly used treatment modality, in addition to surgery, chemotherapy and radiotherapy (32). Vaccines have been investigated for a long time and have been used for the treatment of infectious disease or cancer (33-35), however, progression has remained slower, compared with other forms of immunotherapy (35-37). This is partly due to the weak immunogenicity of the tumor antigens. In the present study the, expression levels of Muc1 in pituitary tumors were examined, and the results demonstrated increased positive expression of Mucl in invasive pituitary tumors. The aim of the present study was to induce potent antitumor T-cell responses to assist in the therapy of pituitary tumors. Thus, Muc1 was used as the tumor antigen and poly I:C, the ligand of TLR3, was selected as the adjuvant to prime the antitumor immune response (37-40). The results of the present study demonstrated that Muc1 + poly I:C successfully induced effective antitumor immune responses.

DCs are considered to be important antigen presenting cells, and they are the most effective cells for antigen presentation and T cell stimulation (41). The maturation of DCs is important for the initiation of an adaptive immune response, thus, the present study detected the presence of certain major histocompatibility complex class II molecules and T-cell costimulatory molecules on the surface of PBMC-derived DCs. The results of the present study revealed that, Mucl + poly I:C significantly enhanced the expression levels of CD40, CD80, CD83 and HLA-DR, in which CD83 is considered a relatively specific marker of mature DCs, and CD14 is a marker 
of monocytes. Treatment with Muc1 + poly I:C increased the expression of CD83 and decreased the expression of CD14, which demonstrated that Muc1 + poly I:C promoted the maturation of the DCs. Additionally, Muc1 + poly I:C stimulated the secretion of TNF- $\alpha$, IL- 6 and IL- $1 \beta$ cytokines, which may assist in attracting neutrophils, monocytes and DCs to inflammatory sites and induce the adaptive immune response $(42,43)$.

It has been reported that the Th1-type immune response is important for protection against viral infections, tumor cells and several pathogens. Th1 cells can secret cytokines, including IFN- $\gamma$ and IL-2, which activate macrophages and are involved in the generation of CTLs. In the present study, the mice injected with Muc1 + poly I:C showed higher levels of IFN- $\gamma$ and IL-2 in the splenocytes when stimulated with Muc1. The CTL response following the final immunization was also examined in the different groups of mice. Supporting the idea that the induction of IFN- $\gamma$ and IL-2 suggested polarization towards the Th1 response, higher specific CTL activity was detected when stimulated with Mucl antigens in vitro.

In the mouse model, immunization with Muc1 + poly I:C induced more extensive production of anti-Muc1, compared with the antigen alone. Notable, activation of the Th1 immune response was marked, as was the switch in the balance of IgG1 and $\operatorname{IgG} 2 \mathrm{a}$, which may contribute to the shift between the Th2 and Th1 immune respons, and was positive for preventing the progression of pituitary tumors.

In conclusion, Muc1 + poly I:C stimulated the expression of costimulatory molecules and promoted the secretion of inflammatory cytokines, IL- 6 , TNF- $\alpha$, IL- $1 \beta$, by human PBMC-derived DCs. In the mouse model, immunization with Muc1 + poly I:C enhanced Muc1-specific antibody titers and induced the shift between the Th2 and Th1 immune response. Therefore, it may offer potential as a useful strategy for the treatment of malignant pituitary tumors.

\section{Acknowledgements}

This study was supported by the National Natural Science Foundation of China (grant no. 81171119).

\section{References}

1. Loyo-Varela M, Herrada-Pineda T, Revilla-Pacheco F and Manrique-Guzman S: Pituitary tumor surgery: Review of 3004 cases. World Neurosurg 79: 331-336, 2013.

2. Salehi F, Kovacs K, Scheithauer BW, Lloyd RV and Cusimano M: Pituitary tumor-transforming gene in endocrine and other neoplasms: A review and update. Endocr Relat Cancer 15 721-743, 2008.

3. Boutros C, Cheng-Robles D and Goldenkranz R: Intestinal neuroendocrine tumor in a patient with pituitary adenoma. A case report and review of the current screening recommendations. J Med Case Rep 1: 140, 2007.

4. Sogani J, Yang W, Lavi E, Zimmerman RD and Gupta A: Sellar collision tumor involving metastatic lung cancer and pituitary adenoma: Radiologic-pathologic correlation and review of the literature. Clin Imaging 38: 318-321, 2014.

5. Ironside JW: Best practice No 172: Pituitary gland pathology. J Clin Pathol 56: 561-568, 2003.

6. Nistor RF: Parasellar classification of pituitary adenomas. Neurosurgery 35: 542-544, 1994.

7. Kovacs K, Horvath E and Vidal S: Classification of pituitary adenomas. J Neurooncol 54: 121-127, 2001.
8. Sánchez-Tejada L, Sánchez-Ortiga R, Moreno-Pérez O, Montañana CF, Niveiro M, Tritos NA and Alfonso AM: Pituitary tumor transforming gene and insulin-like grow th factor 1 receptor expression and immunohistochemical measurement of Ki-67 as potential prognostic markers of pituitary tumors aggressiveness. Endocrinol Nutr 60: 358-367, 2013.

9. Matsuno A, Teramoto A, Takekoshi S, Sanno N, Osamura RY and Kirino T: Expression of plurihormonal mRNAs in somatotrophic adenomas detected using a nonisotopic in situ hybridization method: Comparison with lactotrophic adenomas. Hum Pathol 26: 272-279, 1995.

10. Baskar R, Lee KA, Yeo R and Yeoh KW: Cancer and radiation therapy: Current advances and future directions. Int J Med Sci 9: 193-199, 2012.

11. Bergmann-Leitner ES, Duncan EH and Leitner WW: Identification and targeting of tumor escape mechanisms: A new hope for cancer therapy? Curr Pharm Des 9: 2009-2023, 2003.

12. Ahmed S, Pahwa P, Fields A, Chandra-Kanthan S, Iqbal N, Zaidi A, Reeder B, Plaza FA, Zhu T and Leis A: Predictive factors of the use of systemic therapy in stage iv colorectal cancer: Who gets chemotherapy? Oncology 88: 289-297, 2015.

13. Voloshin T, Voest EE and Shaked Y: The host immunological response to cancer therapy: An emerging concept in tumor biology. Exp Cell Res 319: 1687-1695, 2013.

14. Rini BI, Weinberg V, Fong L, Conry S, Hershberg RM and Small EJ: Combination immunotherapy with prostatic acid phosphatase pulsed antigen-presenting cells (provenge) plus bevacizumab in patients with serologic progression of prostate cancer after definitive local therapy. Cancer 107: 67-74, 2006.

15. Thara E, Dorff TB, Pinski JK and Quinn DI: Vaccine therapy with sipuleucel-T (Provenge) for prostate cancer. Maturitas 69: 296-303, 2011

16. Mao Q, Li L, Zhang C, Sun Y, Liu S and Cui S: Clinical effects of immunotherapy of DC-CIK combined with chemotherapy in treating patients with metastatic breast cancer. Pak J Pharm Sci 28 (3 Suppl): 1055-1058, 2015.

17. Shi YJ, Ren HY, Cen XN, Dong YJ, Ma MX, Zhao YL, Zhu Y and Yu JR: Dendritic cells elicit cellular immune response by targeting to capture breast cancer cells. Zhonghua zhong liu za zhi 30: 107-111, 2008 (In Chinese).

18. Chen W, Rains N, Young D and Stubbs RS: Dendritic cell-based cancer immunotherapy: Potential for treatment of colorectal cancer? J Gastroenterol Hepatol 15: 698-705, 2000.

19. Carmi Y, Spitzer MH, Linde IL, Burt BM, Prestwood TR, Perlman N, Davidson MG, Kenkel JA, Segal E, Pusapati GV, et al: Allogeneic IgG combined with dendritic cell stimuli induce antitumour T-cell immunity. Nature 521: 99-104, 2015.

20. Ahmed Ali HA, Di J, Mei W, Zhang YC, Li Y, Du ZW and Zhang GZ: Antitumor activity of lentivirus-mediated interleukin -12 gene modified dendritic cells in human lung cancer in vitro. Asian Pac J Cancer Prev 15: 611-616, 2014.

21. Bilusic $M$, Heery $C$ and Madan RA: Immunotherapy in prostate cancer: Emerging strategies against a formidable foe. Vaccine 29: 6485-6497, 2011.

22. Pardoll D and Drake C: Immunotherapy earns its spot in the ranks of cancer therapy. J Exp Med 209: 201-209, 2012.

23. Corfield AP: Mucins: A biologically relevant glycan barrier in mucosal protection. Biochim Biophys Acta 1850: 236-252, 2015.

24. Kao CJ, Wurz GT, Monjazeb AM, Vang DP, Cadman TB, Griffey SM, Wolf M and DeGregorio MW: Antitumor effects of cisplatin combined with tecemotide immunotherapy in a human MUC1 transgenic lung cancer mouse model. Cancer Immunol Res 2: 581-589, 2014.

25. Pérez-Sánchez J, Estensoro I, Redondo MJ, Calduch-Giner JA, Kaushik S and Sitjà-Bobadilla $\mathrm{A}$ : Mucins as diagnostic and prognostic biomarkers in a fish-parasite model: Transcriptional and functional analysis. PLoS One 8: e65457, 2013.

26. Asano R, Takemura S, Tsumoto K, Sakurai N, Teramae A, Ebara S, Katayose Y, Shinoda M, Suzuki M, Imai K, et al: Functional construction of the anti-mucin core protein (MUC1) antibody MUSE11 variable regions in a bacterial expression system. J Biochem 127: 673-679, 2000.

27. Cao X, Zhang W, Wan T, He L, Chen T, Yuan Z, Ma S, Yu Y and Chen G: Molecular cloning and characterization of a novel CXC chemokine macrophage inflammatory protein-2 gamma chemoattractant for human neutrophils and dendritic cells. J Immunol 165: 2588-2595, 2000. 
28. Costa CI, Delgado IF, de Costa JA, de Carvalho RF, Mouta Sda S Jr, Vianna CO and de Moraes MT: Establishment and validation of an ELISA for the quantitation of HBsAg in recombinant hepatitis B vaccines. J Virol Methods 172: 32-37, 2011.

29. Jones N, Agrawal D, Elrefaei M, Hanson A, Novitsky V, Wong JT and Cao H: Evaluation of antigen-specific responses using in vitro enriched T cells. J Immunol Methods 274 139-147, 2003

30. Holdsworth SR, Kitching AR and Tipping PG: Th1 and Th2 $\mathrm{T}$ helper cell subsets affect patterns of injury and outcomes in glomerulonephritis. Kidney Int 55: 1198-1216, 1999.

31. Muraille E and Leo O: Revisiting the Th1/Th2 paradigm. Scand J Immunol 47: 1-9, 1998

32. Mishra J, Drummond J, Quazi SH, Karanki SS, Shaw JJ, Chen B and Kumar N: Prospective of colon cancer treatments and scope for combinatorial approach to enhanced cancer cell apoptosis. Crit Rev Oncol Hematol 86: 232-250, 2013.

33. Kirkwood JM, Moschos S and Wang W: Strategies for the development of more effective adjuvant therapy of melanoma: Current and future explorations of antibodies, cytokines, vaccines, and combinations. Clin Cancer Res 12 (Suppl): S2331-S2336, 2006.

34. Kirkwood JM, Strawderman MH, Ernstoff MS, Smith TJ, Borden EC and Blum RH: Interferon alfa-2b adjuvant therapy of high-risk resected cutaneous melanoma: The eastern cooperative oncology group trial EST 1684. J Clin Oncol 14: 7-17, 1996.

35. Terando A, Sabel MS and Sondak VK: Melanoma: Adjuvant therapy and other treatment options. Curr Treat Options Oncol 4: 187-199, 2003.
36. Krishnan L, Deschatelets L, Stark FC, Gurnani K and Sprott GD: Archaeosome adjuvant overcomes tolerance to tumor-associated melanoma antigens inducing protective CD8 T cell responses. Clin Dev Immunol 2010: 578432, 2010.

37. Mechl Z and Kopecny J: Current results with surgery and adjuvant chemotherapy in malignant melanoma. Arch Geschwulstforsch 56: 367-371, 1986 (In German).

38. Inao T, Harashima N, Monma H, Okano S, Itakura M, Tanaka T, Tajima Y and Harada M: Antitumor effects of cytoplasmic delivery of an innate adjuvant receptor ligand, poly (I:C), on human breast cancer. Breast Cancer Res Treat 134: 89-100, 2012.

39. Huang YK, Zheng Z, Cheng CX, Wang LY, Li YR and Qiu F: The antitumor effect of the toll-like receptor 3 ligand polyinosinic-cytidylic acid as an adjuvant. Cancer Immunol Immunother 62: 237-244, 2013.

40. Martinez-Gil L, Goff PH, Hai R, Garcia-Sastre A, Shaw ML and Palese P: A Sendai virus-derived RNA agonist of RIG-I as a virus vaccine adjuvant. J Virol 87: 1290-1300, 2013.

41. Ebner S, Ratzinger G, Krosbacher B, Schmuth M, Weiss A, Reider D, Kroczek RA, Herold M, Heufler C, Fritsch P and Romani N: Production of IL-12 by human monocyte-derived dendritic cells is optimal when the stimulus is given at the onset of maturation, and is further enhanced by IL-4. J Immunol 166: 633-641, 2001.

42. Lindstedt M, Johansson-Lindbom B and Borrebaeck CA: Global reprogramming of dendritic cells in response to a concerted action of inflammatory mediators. Int Immunol 14: 1203-1213, 2002.

43. Yang Y, Ochando J, Yopp A, Bromberg JS and Ding Y: IL-6 plays a unique role in initiating c-Maf expression during early stage of CD4 T cell activation. J Immunol 174: 2720-2729, 2005. 